\title{
Leisure Behavior Pattern Stability During the Transition from Adolescence to Young Adulthood
}

\author{
Leslie A. Raymore, ${ }^{1}$ Bonnie L. Barber, ${ }^{2}$ Jacquelynne S. Eccles, ${ }^{3}$ and \\ Geoffrey C. Godbey ${ }^{4}$
}

Leisure is an important context in which human development occurs. Changes in leisure behavior patterns may indicate changing developmental needs or reflect contextual changes that impact leisure behavior. The transition from adolescence to young adulthood provides an excellent opportunity for the study of the stability of leisure behavior as individuals' contexts are changed with the adoption of adult roles and the potential for disnuption of leisure patterns exists. Previous studies investigating leisure and the transition from adolescence to young adulthood have tended to be cross-sectional and focus on specific leisure behaviors rather than identifying patterns of leisure behavior. The present study involved a longitudinal investigation of leisure behavior patterns over a threeyear period during the transition from adolescence to young adulthood, and

This research was supported by Grant No. DBS9215008 to Bonnie L. Barber and Jacquelynne S. Eccles from the National Science Foundation, Grant No. 92-1459-92 from the W. T. Grant Foundation to Eccles and Barber, and by a Spencer Foundation grant to Eccles and Barber. ${ }^{1}$ Assistant Professor at Lincoln University in Christchurch, New Zealand. Received Ph.D. in leisure studies from The Pennsylvania State University. Major research interests include the developmental implications of leisure and constraints on leisure. To whom correspondence should be addressed at Human Sciences Division, P. O. Box 84, Lincoln University, Canterbury, New Zealand.

${ }^{2}$ Associate Professor at the University of Arizona. Received Ph.D. in developmental psychology from the University of Michigan. Major research interests are adolescent and young adult family relationships.

${ }^{3}$ Williard J. McKeachie Collegiate Professor of Psychology at the University of Michigan, Ann Arbor. Received Ph.D. in developmental psychology from UCLA. Research interests included adolescence, identity formation, expectancy-value models of activity choices and achievement, gender roles, and contextual influences on development. Currently Chair of the Mac Arthur Foundation Research Network on Successful Pathways through Middle Childhood.

${ }^{4}$ Professor of Leisure Studies at The Pennsylvania State University. Received Ph.D. from The Pennsylvania State University. Current research interests involve the interaction between leisure and health. 
determined the nature of leisure pattern stability and instability during this period. In general, leisure pattern stability was the most common pathway into young adulthood. The patterns of leisure behavior and the nature of the changes that occurred with the transition from adolescence to young adulthood differed to some degree for males and females, although similarities in patterns and transitions were also found.

\section{INTRODUCTION}

Leisure is generally thought of as a category of activities that are nonproductive economically and that are typically done for their own sake (Larson and Richards, 1994). According to Tinsley and Tinsley (1986), individuals have needs for which leisure behavior is the only source of satisfaction, and individual differences occur in the activities people consider to constitute leisure, since different people have different leisure needs. Furthermore, not all leisure activities can satisfy all leisure needs at all points in an individual's life (Tinsley et al., 1977). People may choose specific leisure behaviors or patterns of leisure behavior to satisfy particular needs, and needs may change during different periods as contexts and roles change (Iso-Ahola, 1980). As a result, individuals add and delete leisure behaviors from their leisure repertoire across the life span.

Some forms of leisure may, however, remain "core" activities to an individual's leisure behavior pattern throughout the life span (Kelly, 1983), and the development of core leisure behaviors or patterns may begin during adolescence, when autonomous leisure decisions begin to be made. The observation of stability in leisure behavior, indicating core patterns of behavior, may be most likely to occur prior to and following a life transition, when individuals' roles and relationships, or ecological contexts, are altered. New patterns of behavior that evolve may or may not incorporate past behaviors, but that are built upon past experiences, may occur following the experience of a life transition (Raymore, 1995).

One major normative life transition is the shift from adolescence to young adulthood, when individuals leave behind so-called youthful freedom and are generally expected to begin to take major responsibility for the different aspects of their lives. Neither developmental nor leisure researchers have carried out in-depth investigations into how specific events in the transition from adolescence to young adulthood are related to leisure behavior. This particular life transition is a critical point at which researchers can examine the plasticity of individuals, as life contexts and developmental opportunities change (Sherrod et al., 1993). In terms of leisure, individuals with patterns or behaviors that remain intact through this major 
transition may provide insight into the stability of the individuals themselves as well as of particular patterns of leisure behavior.

Research examining leisure and this life transition is fraught with numerous methodological problems (Raymore, 1995). Previous studies are primarily cross-sectional, often comparing unrelated groups of adolescents and young adults on participation rates in specific activities rather than overall patterns or orientations towards activity. Alternatively, college students are asked to recall their leisure behavior during adolescence, and comparisons are based upon the present participation and recollections of the past. Such studies generally include a limited range of leisure pursuits; many studies focus on sports or socially desirable activities, ignoring "risky" leisure behaviors such as the use of drugs or alcohol. Due to the general emphasis on frequency of participation in specific leisure activities, little is known about patterns of leisure behavior, especially in terms of intraindividual change or stability during the transition from adolescence to young adulthood.

Leisure is the social institution that occupies the most central place for modern adolescents in Western society (Agnew and Petersen, 1989; Hendry, 1989; Fine et al., 1990). Teenagers generally report leisure behavior as the most enjoyable activity in their lives, whether in or out of school (Csikszentmihalyi and Larson, 1984). While being a source of enjoyment, leisure also plays a key role in development during adolescence. Leisure provides an arena for role experimentation during adolescence, assists in the learning of social norms, and provides a forum in which adolescents can experiment with the challenges that will face them as adults, including issues related to sexuality and aggression (Fine et al., 1990; Iso-Ahola, 1980; Kleiber and Rickards, 1985). In addition, leisure behaviors are developmentally imperative because they provide a link between the childhood world of play and adult contexts that require disciplined commitment (Kleiber et al., 1986). Hendry $(1983,1989)$ and Hendry et al. (1993) suggest that adolescents tend to move from involvement in organized activities to casual activities to commercial activities (those that cost the adolescent money) as the focus of development changes from heterosexual to peer to parental relationships across adolescence.

Kleiber et al. (1986) proposed two categories of leisure behavior during adolescence-relaxed leisure and transitional leisure. Relaxed leisure involves activities that are pleasurable but do not necessarily make a developmental contribution, such as watching television. Transitional leisure, in contrast, has some developmental benefits; this type of leisure occurs when the leisure context demands effort from the adolescent, as in the context of sports or games. Transitional leisure activities help adolescents develop the ability to experience freedom and intrinsic motivation in contexts where 
some behaviors may be obligatory, which the authors suggest have carryover to all domains of psychosocial functioning.

Shaw et al. (1995) have contributed to the understanding of potential links between identity development and leisure participation, finding that specific leisure activities may have beneficial effects (e.g., development of independence) as well as detrimental effects (e.g., affirmation of gender stereotypes) on overall identity development. Adams et al. (1979) suggested that recreation (or leisure) identity is an important component of identity formation. The role of leisure during adolescence has, however, rarely been examined in relation to its impact on young adulthood.

Defining the point of transition from adolescence to young adulthood can pose problems for researchers. Some use high school graduation as a marker of the transition (see Fasick, 1988), others use age alone as an indicator (see Schulenberg et al., 1996), while still others use a combination of age with predictor variables based on events that can accompany the transition (see Hartnagel, 1996). According to Greene et al. (1992), there are four major life transition events that can occur during the transition from adolescence to young adulthood: Leaving home, beginning work or going to college, establishing a long-term relationship via marriage or cohabitation, and becoming a parent. Each of these transition events could potentially have great influence on leisure behavior because of the accompanying changes in context, and each event may have a differential effect on males and females.

Gender differences have often been viewed as peripheral to hypotheses of leisure research (Henderson and Bialeschki, 1989), yet while men and women may share similar lifestyles, they may have different leisure needs and derive different forms of satisfaction from similar leisure activities (Colley, 1984). Gender differences in leisure activity preferences and orientations are visible early in childhood (Eccles and Harold, 1991; Maudlin and Meeks, 1990), and are evident in both adolescent (Berk and Goebel, 1987; Furlong et al., 1990; Crompton et al., 1981; Garton and Pratt, 1991) and young adult (Crawford and Huston, 1993; Horna, 1989; Johnson et al., 1992; Rapoport and Rapoport, 1975; Witt and Goodale, 1981) leisure behavior. Researchers must therefore accommodate gender differences when developing models for understanding leisure across this life transition.

The choices people make regarding leisure behavior are limited to activities compatible with their present contexts. When contexts change with a life transition the resources, opportunities, and role expectations of an individual may also change, affecting both the individual and the social environment (Kelly, 1983; Silbereisen, Noack and von Eye, 1992). Developing an understanding of the nature of leisure behavior patterns during adolescence and young adulthood, and attempting to identify patterns of intrain- 
dividual stability or instability in leisure behavior, may help developmental and leisure researchers begin to understand the role that life transitions play in leisure behavior across the life span.

\section{PURPOSE OF STUDY}

The purpose of this study was to examine leisure behavior during both adolescence and the period of transition into young adulthood in order to determine whether leisure patterns could be identified at these two points in the life span. If patterns could be identified, the next step was to determine the stability and instability of leisure behavior patterns during the transition from adolescence to young adulthood. The present study also sets the stage for research that examines the role that specific life transition events play in the stability or instability of leisure patterns.

\section{METHOD}

\section{Selection of Subjects}

The data for this investigation were from the Michigan Study of Adolescent Life Transitions (MSALT), a longitudinal investigation that began in 1983. MSALT was originally initiated as a study of the impact of junior high school environment and family environment on young adolescents' interests, motivation, and achievement-related self-concepts (Eccles, Wigfield et al., 1989). The original group of subjects consisted of 6th grade students from ten predominantly white middle- and lower-middle-class school districts in Southeastern Michigan.

The data utilized in this investigation come from Waves 6 and 7 of MSALT. Wave 6 data collection occurred in the spring of 1990 when subjects were in the 12 th grade; the response rate was approximately $80 \%$. Wave 7 data collection took place in the late summer and fall of 1992 and winter of 1993, two to three years after high school. The Wave 7 response rate was approximately $80 \%$ of the eligible pool. Wave 6 was used in this study to represent adolescents' leisure behaviors prior to the transition to young adulthood. Wave 7 was used to represent young adults' leisure behaviors during that transition. In this study we have used departure from high school as a starting point of the transition to young adulthood (see Fasick, 1988).

The criterion for the inclusion of subjects in this study was participation at both Wave 6 and Wave 7 of data collection; subjects were initially included in the data analysis based on the presence of data at both waves. 
Based on this requirement, data existed for 602 females and 352 males, leading to a total pool of 954 participants. The average age of subjects was approximately 18 years at Wave 6 and approximately 21 years at Wave 7 .

\section{Measures}

During Wave 6, adolescents were administered a 57 page questionnaire in their high school auditorium or cafeteria during two 50-minute school periods. Research staff members were present to answer any questions. In order to maintain as large a sample as possible, students who were absent from school on the day of administration but who had participated in previous waves were sent questionnaires with postage paid envelopes. There was no financial compensation for completion of the instrument. During Wave 7, the subjects from the same pool as at Wave 6 were mailed a three-book questionnaire that they were to fill out and return by mail. The first book, in which the items under investigation were located, was 45 pages long. An incentive of $\$ 20$ was sent to the participant following completion of the three-book instrument.

The leisure behaviors were measured on an ordinal scale. The leisure behaviors included in the survey at both waves are listed in Table I. Leisure behaviors traditionally studied by leisure researchers as well as risk behavior measures were included in the analyses. The response categories for the traditional leisure behaviors were (1) None, (2) 1 hour or less, (3) 2-3 hours, (4) 4-6 hours, (5) 7-10 hours, (6) 11-15 hours, (7) 16-20 hours, (8) 21 or more hours per week. The risk behavior measures used the following categories to indicate frequency of engaging in the activity in the previous six months (1) None, (2) once, (3) 2-3 times, (4) 4-6 times, (5) 7-10 times, (6) 11-20 times, and (7) 21 or more times. "Drinking alcohol" at Wave 6 had an extra category, with (7) 21 to 30 times and (8) 31 times or more. Television at Wave 7 was measured by the response categories "watching sports on TV" and "watching other shows on TV"; otherwise, measures were the same at both waves. A description of the sample by gender is located in Table II.

Also included was the socioeconomic index (SEI) of mothers' occupations (Entwisle and Astone, 1994) as an indicator of socioeconomic status. Occupations were coded in a two-step process. First, mothers' occupations were coded according to the categories in the 1980 U.S. Census occupational coding system. The census codes were then converted to a 100-point scale, based on the SEI, which takes into account the education required and the salaries paid to persons in a particular occupation. 
Table I. Leisure Behaviors Measured at Wave 6 and Wave 7

\begin{tabular}{|c|c|c|}
\hline & $\begin{array}{c}\text { Wave 6 } \\
\text { (Adolescence, 12th Grade) }\end{array}$ & $\begin{array}{c}\text { Wave } 7 \\
\text { (Young Adulthood, Two/Three } \\
\text { Years Later) }\end{array}$ \\
\hline \multicolumn{3}{|c|}{ About how many hours do you usually spend each week (ordinal category answers): } \\
\hline 1. & Hanging out with friends & $\begin{array}{l}\text { Hanging out with friends other than your } \\
\text { spouse/romantic partner }\end{array}$ \\
\hline 2. & $\begin{array}{l}\text { Taking part in an organized sport } \\
\text { doing other athletic or sports activities }\end{array}$ & $\begin{array}{l}\text { Taking part in an organized competitive } \\
\text { sport doing other athletic or sports } \\
\text { activities }\end{array}$ \\
\hline 3. & Reading for fun & Reading for fun \\
\hline 4. & Doing things with your family & Doing things with your parents \\
\hline 5 . & Playing a musical instrument & Playing a musical instrument \\
\hline 6 . & Providing volunteer or community service & Providing volunteer or community service \\
\hline 7. & Doing religious activities & $\begin{array}{l}\text { How often do you attend religious services } \\
\text { (never, rarely, once or twice a month, } \\
\text { once a week or more) }\end{array}$ \\
\hline 8. & $\begin{array}{l}\text { Participating in any school clubs or } \\
\text { organizations }\end{array}$ & Participating in any clubs or organizations \\
\hline 9. & Watching TV & $\begin{array}{l}\text { Watching sports on TV } \\
\text { Watching other shows on TV }\end{array}$ \\
\hline \multicolumn{3}{|c|}{$\begin{array}{c}\text { About how often in (the last) six months did you do the things listed below } \\
\text { (ordinal category answers): }\end{array}$} \\
\hline & $\begin{array}{l}\text { Drink alcohol } \\
\text { Get drunk }\end{array}$ & $\begin{array}{l}\text { Drink alcohol } \\
\text { Get drunk }\end{array}$ \\
\hline & $\begin{array}{l}\text { Use chemicals or drugs other than } \\
\text { marijuana } \\
\text { Use marijuana or hash }\end{array}$ & $\begin{array}{l}\text { Use other chemicals or drugs to get high } \\
\text { Use marijuana }\end{array}$ \\
\hline 12. & $\begin{array}{l}\text { Do something you knew was dangerous } \\
\text { just for the thrill of it } \\
\text { Do some pretty risky things because it } \\
\text { was a real kick }\end{array}$ & $\begin{array}{l}\text { Do something you knew was dangerous } \\
\text { just for the thrill of it } \\
\text { Do some pretty risky things because it } \\
\text { was a real kick }\end{array}$ \\
\hline
\end{tabular}

\section{Cluster Analysis}

According to Romesburg (1979), there are three features of cluster analysis that make it a valuable procedure for leisure researchers: (1) Cluster analysis allows the researcher to find sets of objects that are similar (as opposed to orthogonal), (2) cluster analysis allows the researcher to describe the characteristics or attributes of cluster members on the measures 
Table II. Description of Sample on Leisure Variables

\begin{tabular}{|c|c|c|c|c|c|c|}
\hline \multirow[b]{2}{*}{ Variable } & \multicolumn{3}{|c|}{ Females } & \multicolumn{3}{|c|}{ Males } \\
\hline & Mean & $S D$ & $\mathrm{n}$ & Mean & $S D$ & $\mathrm{n}$ \\
\hline & \multicolumn{6}{|c|}{ Wave 6} \\
\hline Hang with friends & 5.44 & 1.73 & 600 & 5.61 & 1.67 & 351 \\
\hline Sport behavior & 2.44 & 1.69 & 601 & 3.44 & 1.88 & 352 \\
\hline Reading & 2.48 & 1.35 & 597 & 2.31 & 1.34 & 350 \\
\hline Family time & 3.61 & 1.57 & 600 & 3.28 & 1.30 & 352 \\
\hline Playing instrument & 1.43 & 1.05 & 602 & 1.61 & 1.42 & 352 \\
\hline Volunteer work & 1.46 & .89 & 599 & 1.36 & .76 & 348 \\
\hline Religion & 1.69 & 1.03 & 600 & 1.72 & 1.12 & 347 \\
\hline Clubs/organizations & 2.14 & 1.41 & 566 & 1.83 & 1.33 & 339 \\
\hline Watching TV & 3.83 & 1.51 & 601 & 4.22 & 1.63 & 348 \\
\hline Alcohol use & 3.49 & 2.16 & 553 & 4.05 & 2.32 & 305 \\
\hline Drug use & 1.39 & .93 & 555 & 1.66 & 1.24 & 308 \\
\hline \multirow[t]{2}{*}{ Do things for kicks } & 2.32 & 1.35 & 553 & 3.35 & 1.63 & 307 \\
\hline & \multicolumn{6}{|c|}{ Wave 7} \\
\hline Hang with friends & 5.01 & 2.02 & 594 & 5.48 & 1.96 & 342 \\
\hline Sport behavior & 2.17 & 1.17 & 596 & 3.01 & 1.40 & 345 \\
\hline Reading & 2.88 & 1.52 & 594 & 2.66 & 1.49 & 345 \\
\hline Family time & 3.23 & 1.69 & 598 & 2.73 & 1.48 & 351 \\
\hline Playing instrument & 1.26 & .80 & 600 & 1.50 & 1.24 & 352 \\
\hline Volunteer work & 1.50 & .95 & 599 & 1.54 & 1.15 & 352 \\
\hline Religion & 2.33 & .94 & 600 & 2.15 & .94 & 350 \\
\hline Clubs/organizations & 1.85 & 1.34 & 599 & 1.94 & 1.51 & 352 \\
\hline Watching TV & 4.44 & 1.71 & 592 & 4.97 & 1.87 & 345 \\
\hline Alcohol use & 3.89 & 1.85 & 605 & 4.53 & 2.07 & 350 \\
\hline Drug use & 1.45 & .95 & 605 & 1.75 & 1.34 & 350 \\
\hline Do things for kicks & 1.83 & 1.06 & 605 & 2.74 & 1.49 & 351 \\
\hline
\end{tabular}

used to define the clusters, and (3) the researcher decides which cluster solution makes the most theoretical sense. Also, cluster analysis is based on simple mathematical tasks such as addition and subtraction. Therefore, according to Romesburg (1979), the results are highly communicable to people who are not experts on the procedure.

While Romesburg wrote about the benefits of cluster analysis in 1979, use of the procedure in leisure research has been limited. Factor analysis, which focuses on differences between group characteristics instead of similarities, is by far the more common procedure. When cluster analysis has been utilized, it is often used to develop taxonomies of leisure behavior and benefits (see Tinsley and Johnson, 1984). In terms of adolescent or transition related leisure research, Kleiber et al. (1986) utilized a "visual inspection of means" to develop two clusters of leisure activities, and sug- 
gested that actual analysis would be useful. Cluster analysis was then successfully used by Ellis and Rademacher (1987) on the Kleiber et al. (1986) data in order to develop taxonomies of adolescent free time activities. However, the authors' goal was not to cluster individuals based on their participation in activities, but activities based on participation. Cluster analysis has also been used to develop typologies of marriage, where leisure is considered an important variable (Johnson et al., 1992). Studying the same people on the same leisure behaviors and deriving cluster solutions at two or more points in time will increase our knowledge regarding the stability of clusters, a topic that has been underresearched (Ellis and Rademacher, 1987).

Since the statistical analyses in the present research involved cluster analyses, the data at Waves 6 and 7 were prepared in a manner that would increase the interpretability of the cluster solutions. First, leisure behaviors that were overlapping within a wave of data collection were averaged, creating a single variable in order to avoid a heavier weighting of that behavior when cluster solutions were being calculated.

Due to the potential differential effects of life transitions on males and females, all cluster analyses were carried out separately for each gender. Prior to performing the cluster analyses, subjects were randomly assigned to one of two groups within each gender (i.e., Group A Females/Group B Females). The purpose of this step in the treatment of data involved demonstrating the reliability of the cluster solutions-clusters that appeared in both Group A and Group B and that had acceptable correlations between solutions would be included in the final cluster solution.

The use of ordinal rather than interval or ratio level data does not reduce the interpretability of the cluster analysis; cluster analysis is an appropriate statistical tool for identifying groups of subjects using ordinal level data (Johnson et al., 1992). In order to provide common units of measurement for the cluster analysis, leisure behavior data were converted to $z$ scores, thus eliminating the higher weighting of items measured on larger scales (Norusis, 1990).

Cluster analyses were then carried out in order to create a taxonomy of leisure behavior patterns based on leisure behavior participation.

\section{RESULTS}

Eight cluster solutions were generated. The method for combining clusters using SPSS was the average linkage between groups method, which "defines the distance between two clusters as the average of the distances between all pairs of cases in which one member of the pair is from each 
of the clusters" (Norusis, 1990, p. 361). This agglomerative, hierarchical method uses information about all pairs of distances rather than the nearest or the furthest pairs. The distance measure used was the cosine measure, which is a pattern similarity measure examining the shape of patterns of behavior (Aldenderfer and Blashfield, 1984).

While almost any data set can produce a cluster solution, one of the purposes of the study was to create reliable, replicable, and interpretable clusters of leisure behavior for males and females during adolescence and young adulthood. In order to achieve this goal, Groups A and B were compared within waves for each gender. Only clusters that replicated satisfactorily within waves and genders were included in the final cluster solutions. Correlations between Group A and B clusters for each of the final clusters are reported in Table III. Correlations between the two groups were calculated based on the pattern similarity of the two cluster solutions.

The correlations between the individual clusters for the leisure behavior patterns of each of the Group A and Group B clusters during each wave could be considered high enough to demonstrate reliable clusters, since all correlations were above $r=.70$. In each case, except that of Wave 7 females, all subjects with complete data could be included in the final composite of leisure behavior patterns. In the case of Wave 7 females, a group of 45 females in the " $\mathrm{B}$ " solution had characteristics that were not replicated in the " $\mathrm{A}$ " solution. These females were dropped from further analyses as their leisure behavior patterns as identified by cluster analysis were not deemed reliable.

Table III. Correlations Between A and B Clusters by Gender per Wave

\begin{tabular}{lcccc}
\hline & Wave 6 & $n$ & Wave 7 & $n$ \\
\hline Females & & & & \\
$\quad$ Risky & .974 & 128 & .964 & 127 \\
Positive Active & .980 & 181 & .947 & 117 \\
$\quad$ Diffused & .977 & 135 & .927 & 135 \\
$\quad$ Home Based & .792 & 62 & .985 & 154 \\
Males & & & & \\
$\quad$ Risky & .982 & 94 & .978 & 105 \\
Positive Active & .923 & 76 & - & - \\
$\quad$ Diffused & .776 & 44 & .910 & 102 \\
$\quad$ Jocks & .861 & 54 & - & - \\
Active (Formal) & - & - & .961 & 86 \\
Active (Informal) & - & - & .763 & 31 \\
\hline
\end{tabular}


Readers should note that not all members of a given cluster or leisure behavior pattern necessarily participate in all of the activities that define the cluster, but that in general subjects fit the particular pattern identified in the cluster analysis.

\section{Leisure Behavior Patterns}

Patterns of leisure behavior could be seen to emerge when the characteristics of the combined clusters were examined relative to the other clusters within the same wave and gender. Each of these patterns is described below. The labels of the patterns were based on leisure behavior relative to other males or females at the same point in time. Similar labels are intended to denote similar, but not necessarily identical, patterns of leisure behavior.

\section{Female Leisure Behavior Patterns}

A tabular summary of the female leisure behavior patterns during adolescence (Wave 6) and the transition into young adulthood (Wave 7) that emerged as a result of the cluster analyses are presented in Tables IV and $\mathrm{V}$. Underlined scores represent the pattern with the highest score on a particular leisure behavior.

Table IV. Female Wave 6 Cluster Means and Standard Deviations for Leisure Activities

\begin{tabular}{llcccc}
\hline & \multicolumn{5}{c}{ Cluster } \\
\cline { 2 - 6 } \multicolumn{1}{c}{ Activity } & $\begin{array}{c}\text { Risky } \\
(n=128)\end{array}$ & $\begin{array}{c}\text { Positive } \\
\text { Active } \\
(n=181)\end{array}$ & $\begin{array}{c}\text { Diffused } \\
(n=135)\end{array}$ & $\begin{array}{c}\text { Home } \\
\text { Based } \\
(n=62)\end{array}$ & $\begin{array}{c}\text { Sample } \\
\text { Mean }^{a} \\
(N=506)\end{array}$ \\
\hline Hang with friends & $\underline{6.36(1.43)}$ & $\mathbf{5 . 1 0 ( 1 . 5 4 )}$ & $5.17(1.85)$ & $5.94(1.57)$ & $5.54(1.69)$ \\
Sport behavior & $2.29(1.46)$ & $\mathbf{3 . 2 8}(2.07)$ & $1.78(1.15)$ & $2.11(1.22)$ & $2.49(1.73)$ \\
Reading & $2.17(1.26)$ & $2.51(1.04)$ & $2.14(.93)$ & $\underline{3.63}(2.11)$ & $2.46(1.33)$ \\
Family time & $3.27(1.23)$ & $3.83(1.32)$ & $2.84(1.24)$ & $4.79(2.10)$ & $3.54(1.52)$ \\
Playing instrument & $1.30(.88)$ & $1.96(1.46)$ & $1.07(.26)$ & $1.19(.67)$ & $1.46(1.08)$ \\
Volunteer work & $1.23(.59)$ & $2.08(1.22)$ & $1.09(.29)$ & $1.21(.48)$ & $1.49(.93)$ \\
Religion & $1.38(.60)$ & $2.30(1.27)$ & $1.20(.47)$ & $1.58(.78)$ & $1.69(1.01)$ \\
Clubs/organizations & $1.77(1.23)$ & $\underline{3.03}(1.54)$ & $1.50(.85)$ & $1.81(1.20)$ & $2.15(1.43)$ \\
Watching TV & $3.68(1.38)$ & $3.54(1.33)$ & $3.71(1.43)$ & $4.87(1.95)$ & $3.78(1.51)$ \\
Alcohol use & $5.88(1.41)$ & $2.56(1.72)$ & $2.69(1.61)$ & $3.32(2.11)$ & $3.53(2.17)$ \\
Drug use & $2.22(1.48)$ & $1.07(.26)$ & $1.10(.31)$ & $1.24(.64)$ & $1.39(.94)$ \\
Do things for kicks & $\mathbf{3 . 6 1}(1.47)$ & $2.01(1.06)$ & $1.83(.96)$ & $1.75(.88)$ & $2.33(1.36)$ \\
\hline
\end{tabular}

${ }^{a}$ Mean represents average score for ordinal categories. 
Table V. Female Wave 7 Cluster Means and Standard Deviations for Leisure Activities

\begin{tabular}{llllll}
\hline & \multicolumn{5}{c}{ Cluster } \\
\cline { 2 - 6 } \multicolumn{1}{c}{ Activity } & $\begin{array}{c}\text { Risky } \\
(n=12)\end{array}$ & $\begin{array}{c}\text { Positive } \\
\text { Active } \\
(n=117)\end{array}$ & $\begin{array}{c}\text { Diffused } \\
(n=135)\end{array}$ & $\begin{array}{c}\text { Home } \\
\text { Based } \\
(n=154)\end{array}$ & $\begin{array}{c}\text { Sample } \\
\text { Mean } \\
(N=533)\end{array}$ \\
\hline Hang with friends & $\underline{6.00(1.91)}$ & $5.67(1.67)$ & $4.41(2.04)$ & $4.02(1.84)$ & $4.95(2.05)$ \\
Sport behavior & $2.18(1.15)$ & $\underline{3.17}(1.26)$ & $1.71(.76)$ & $1.50(.68)$ & $2.08(1.15)$ \\
Reading & $2.91(1.66)$ & $2.75(1.36)$ & $2.47(1.04)$ & $\underline{3.20}(1.64)$ & $2.85(1.48)$ \\
Family time & $2.83(1.56)$ & $3.08(1.72)$ & $2.96(1.34)$ & $\underline{3.86}(1.90)$ & $3.22(1.70)$ \\
Playing instrument & $1.20(.55)$ & $\underline{1.50}(1.19)$ & $1.12(.37)$ & $1.03(.18)$ & $1.20(.67)$ \\
Volunteer work & $1.20(.45)$ & $\underline{2.41}(1.12)$ & $1.43(1.10)$ & $1.12(.40)$ & $1.50(.96)$ \\
Religion & $2.02(.72)$ & $2.73(.89)$ & $2.93(1.01)$ & $1.84(.68)$ & $2.35(.95)$ \\
Clubs/organizations & $1.69(1.31)$ & $\mathbf{3 . 2 4}(1.56)$ & $\mathbf{1 . 4 9}(.85)$ & $1.13(.42)$ & $1.82(1.34)$ \\
Watching TV & $4.55(1.69)$ & $4.14(1.50)$ & $3.70(1.41)$ & $\mathbf{5 . 3 1}(1.74)$ & $4.46(1.71)$ \\
Alcohol use & $\underline{5.53}(1.17)$ & $4.17(1.73)$ & $2.70(1.42)$ & $3.49(1.83)$ & $3.97(1.85)$ \\
Drug use & $\mathbf{2 . 1 8}(1.41)$ & $1.25(.56)$ & $1.10(.42)$ & $1.41(.86)$ & $1.48(.98)$ \\
Do things for kicks & $\mathbf{2 . 7 0}(1.40)$ & $1.87(.91)$ & $1.44(.76)$ & $1.52(.66)$ & $1.86(1.08)$ \\
\hline
\end{tabular}

${ }^{a}$ Mean represents average score for ordinal categories.

The most common leisure behavior pattern for adolescent females was labeled as Positive Active $(n=181,36 \%)$ because the leisure activities defining the pattern revolved around societally valued leisure activities. Members of this cluster were higher on sport behavior, playing an instrument, volunteer work, doing religious activities, and participating in clubs or organizations than their peers. Members of this group spent less time than their peers hanging out with friends and watching TV, and used alcohol and drugs less frequently. The Positive Active cluster was also apparent during young adulthood but became the least common leisure pattern for young adult females $(n=117,22 \%)$. Members of this cluster had the highest participation rates in the same activities as during adolescence, but were not lowest on any activity.

The second most common leisure behavior pattern for females during adolescence was labeled "Diffused," based on Marcia's (1966) concept of an ego identity status where there is no evidence of commitment to, in this case, a leisure pattern. Members of the Diffused cluster during adolescence did not have the highest participation rates in any of the twelve leisure activities, and were lowest on seven activities, including sports, reading, family time, playing an instrument, volunteer work, religion, and clubs or organizations. The Diffused pattern was also apparent during young adulthood for females; however, people having this pattern during young adulthood spent more time involved in religious activities than any other group, suggesting that perhaps some females who were Positive Active during adolescence maintained their religious participation during young adulthood 
but otherwise became Diffused in their leisure behavior. The female young adult Diffused cluster was lowest in reading, drug use, and doing things for kicks.

The third most common leisure pattern for females during adolescence was labeled "Risky" $(n=128,25 \%)$. Adolescent females with the Risky pattern of leisure behavior tended to hang out with friends more, use alcohol more frequently, use drugs more frequently, and do things for kicks more frequently than their peers. These females did not have the lowest participation levels in any of the leisure activities in the survey. The Risky cluster also appeared during young adulthood for the females $(n=127$, $24 \%$ ) and had the highest frequency in the same behaviors as during adolescence. The young adult group of Risky females, however, were lowest on family time compared to their peers.

The final leisure behavior pattern for adolescent females was labeled "Home Based," since these females spent the most time with family, and had the highest rates of reading and watching television-activities that typically occur in the home. During adolescence this group did not have the lowest frequency for any of the leisure behaviors. The Home Based leisure pattern was also apparent during young adulthood for females; however, while the high participation defining characteristics (family, reading, TV) remained the same, Home Based young adult females were the lowest on six leisure activities. These activities included hanging with friends, sports, playing an instrument, volunteer work, religion, and participation in clubs or organizations.

To summarize, the overall patterns of leisure behavior for females remained the same during adolescence and the transition into young adulthood; Positive Active, Risky, Diffused, and Home Based patterns could be identified at both points. While the characteristics defining the patterns did not remain exactly the same at the two points in time, the general patterns were clearly identifiable. The relative frequency of each type of pattern did not remain stable; for example, while Positive Active was the most popular pattern for adolescent females, it was the least popular pattern of leisure behavior during young adulthood.

\section{Male Leisure Behavior Patterns}

While identifiable patterns existed for males during both adolescence and young adulthood, the patterns differed slightly at the two different points in the life span. During adolescence, clusters were labeled as "Risky," "Positive Active," "Diffused," and "Jocks." During young adulthood, clusters were labelled "Risky," "Active (Formal)," "Diffused," and 
"Active (Informal)." Clusters that appeared during both points in time will be described below, and will be followed by a description of the clusters that appeared at only one point. The cluster characteristics for the males at Waves 6 and 7 are presented in Tables VI and VII.

During both adolescence $(n=94,34 \%)$ and the transition into young adulthood $(n=105,32 \%)$, the most common pattern of leisure behavior

Table VI. Male Wave 6 Cluster Means and Standard Deviations for Leisure Activities

\begin{tabular}{llllll}
\hline & \multicolumn{5}{c}{ Cluster } \\
\cline { 2 - 6 } \multicolumn{1}{c}{ Activity } & $\begin{array}{c}\text { Risky } \\
(n=94)\end{array}$ & $\begin{array}{c}\text { Positive } \\
\text { Active } \\
(n=86)\end{array}$ & $\begin{array}{c}\text { Diffused } \\
(n=44)\end{array}$ & $\begin{array}{c}\text { Jock } \\
(n=54)\end{array}$ & $\begin{array}{c}\text { Sample } \\
\text { Mean }\end{array}$ \\
$(N=278)$
\end{tabular}

${ }^{a}$ Mean represents average score for ordinal categories.

Table VII. Male Wave 7 Cluster Means and Standard Deviations for Leisure Activities

\begin{tabular}{llllll}
\hline & \multicolumn{5}{c}{ Cluster } \\
\cline { 2 - 6 } \multicolumn{1}{c}{ Activity } & $\begin{array}{c}\text { Risky } \\
(n=105)\end{array}$ & $\begin{array}{c}\text { Active } \\
(\text { Formal) } \\
(n=86)\end{array}$ & $\begin{array}{c}\text { Diffused } \\
(n=102)\end{array}$ & $\begin{array}{c}\text { Active } \\
(\text { Informal) } \\
(n=31)\end{array}$ & $\begin{array}{c}\text { Sample } \\
\text { Mean }^{a} \\
(N=324)\end{array}$ \\
\hline Hang with friends & $6.29(1.57)$ & $5.98(1.72)$ & $3.77(1.61)$ & $6.94(1.69)$ & $5.48(1.97)$ \\
Sport behavior & $2.94(1.10)$ & $3.48(1.31)$ & $2.55(1.441)$ & $3.71(1.46)$ & $3.04(1.39)$ \\
Reading & $2.17(.96)$ & $2.51(1.21)$ & $2.61(1.56)$ & $\frac{4.68}{(.88)}$ & $2.64(1.49)$ \\
Family time & $2.84(1.14)$ & $2.44(1.55)$ & $2.57(1.09)$ & $\underline{3.74}(1.04)$ & $2.73(1.50)$ \\
Playing instrument & $1.14(.45)$ & $1.50(1.27)$ & $1.24(.73)$ & $1.94(.48)$ & $1.34(.96)$ \\
Volunteer work & $1.10(.35)$ & $2.31(1.55)$ & $1.21(.60)$ & $1.68(.55)$ & $1.51(1.08)$ \\
Religion & $1.90(.83)$ & $2.84(1.00)$ & $1.93(.80)$ & $1.77(.93)$ & $2.15(.95)$ \\
Clubs/organizations & $1.34(.86)$ & $\underline{3.29}(1.91)$ & $1.46(.91)$ & $2.00(.84)$ & $1.96(1.52)$ \\
Watching TV & $5.17(1.77)$ & $5.02(1.95)$ & $4.57(1.81)$ & $5.74(1.53)$ & $5.00(1.88)$ \\
Alcohol use & $\underline{6.05(1.25)}$ & $4.42(1.94)$ & $2.91(1.66)$ & $5.02(1.84)$ & $4.53(2.06)$ \\
Drug use & $2.51(1.68)$ & $1.26(.76)$ & $1.09(.31)$ & $2.44(.26)$ & $1.73(1.34)$ \\
Do things for kicks & $3.30(1.42)$ & $2.54(1.24)$ & $1.91(1.18)$ & $3.87(1.28)$ & $2.72(1.48)$ \\
\hline
\end{tabular}

${ }^{a}$ Mean represents average score for ordinal categories. 
for males was the Risky pattern. At both times Risky males used alcohol and drugs more frequently than their non-Risky counterparts. During adolescence members of this cluster also reported that they did things for kicks more frequently. Adolescent Risky males spent the least time reading and doing volunteer work, which was also true during young adulthood. Young adult Risky males also spent the least time playing a musical instrument and involved in clubs or organizations.

Members of the cluster labeled "Diffused" did not have the highest participation in any of the leisure activities. During adolescence, members of this cluster ( $n=44,16 \%$ ) were lowest on sports, family time, religion, clubs or organizations, and watching television. During young adulthood males with a Diffused leisure pattern $(n=102,31 \%)$ were lowest on hanging out with friends, sport behavior, watching television, alcohol use, drug use, and doing things for kicks.

The pattern labeled "Positive Active" was apparent during adolescence. Members of this cluster $(n=86,31 \%)$ had the highest participation rates in reading, family time, playing an instrument, volunteer work, religion, and clubs or organizations compared to their peers, and the lowest participation rates in hanging out with friends, alcohol use, drug use, and doing things for kicks. During young adulthood, two different "Active" types were identified. Subjects who had the Active (Formal) pattern $(n=86,27 \%)$ were highly involved in formal organizations compared to their peers, participating at higher rates in volunteer work, religious activities, and clubs or organizations. Members of this cluster had the least amount of family time of any of the patterns. The Active (Informal; $n=31,10 \%$ ) pattern consisted of people who were highly involved in a number of activities compared to their peers, including hanging out with friends, sports, reading, playing an instrument, watching television, and doing things for kicks. Young adult males with this pattern had the lowest rates of participation in clubs or organizations compared to their peers.

Finally, during adolescence a pattern that was labeled "Jocks" emerged. Males with this leisure pattern $(n=54,19 \%)$ tended to spend more time hanging with their friends, involved in sport, and watching television, than their peers.

To summarize, the patterns of leisure behavior changed slightly during young adulthood; two types of "Active" males became apparent. The emergent patterns of leisure behavior for males did not include a pattern that revolved around the home. The most common leisure behavior pattern during both adolescence and young adulthood for males was Risky leisure. 


\section{Socioeconomic Status and Leisure Pattern}

Analyses of variance (ANOVAs) were carried out in order to determine whether leisure patterns were associated with the SEI of mothers' occupation during adolescence and young adulthood for both sexes. The ANOVA examining the relationship of female adolescent leisure patterns to SEI approached significance $(\mathrm{N}=299, F[3,296]=2.3, p=.08)$; a Tukey-B follow-up test indicated that a significant difference $(p=.05)$ in SEI existed between the Risky ( $M=51.0, S D=16.7)$ and the Home Based $(M=42.3, S D=16.6)$ leisure patterns. A score of 51 corresponds to occupations such as health technicians and sales occupations supervisors, and a score of 42.3 corresponds to occupations such as millwrights and optical goods workers (Entwisle and Astone, 1994).

The ANOVA to determine whether SEI differed between females' patterns during young adulthood was significant $(\mathrm{N}=299, F[3,296]=3.23$, $p=.03$ ). Young adult females from the Positive Active pattern were from significantly higher $(p=.05)$ SEI backgrounds $(M=53.2, S D=16.4)$ than females from the Diffused $(M=45.7, S D=16.8)$ and the Home Based $(M=46.1, S D=17.6)$ patterns. An SEI score of 53.2 corresponds approximately to properties and real estate managers, 45.7 and 46.1 represent occupations such as stenographers and ushers, respectively.

For males, leisure patterns were not significantly related to SEI during either adolescence $(\mathrm{N}=164, F[3,161]=.94, p=.42)$ or young adulthood $(\mathrm{N}=164, F[3,161]=1.09, p=.35)$.

\section{Leisure Patterns During the Transition From Adolescence to Young Adulthood}

Participants who had complete leisure data at both adolescence and young adulthood, and who were therefore members of a cluster during both points in time, were included in the subsequent treatment of data. Intraindividual pathways of leisure behavior during the transition from adolescence to young adulthood were determined. Female pathways are presented in Fig. 1, male pathways in Fig. 2. Stability and change in leisure behavior pattern could only be described in cases where the same type of leisure pattern appeared during both adolescence and young adulthood. Stable pathways are shaded in grey in the figures.

For females, the three most common paths based on percentages within each of the four transition solutions, thus controlling for the size of each original adolescent pattern, were the stable Home Based $(55 \%$ of Home Based people remained Home Based during young adulthood), the 


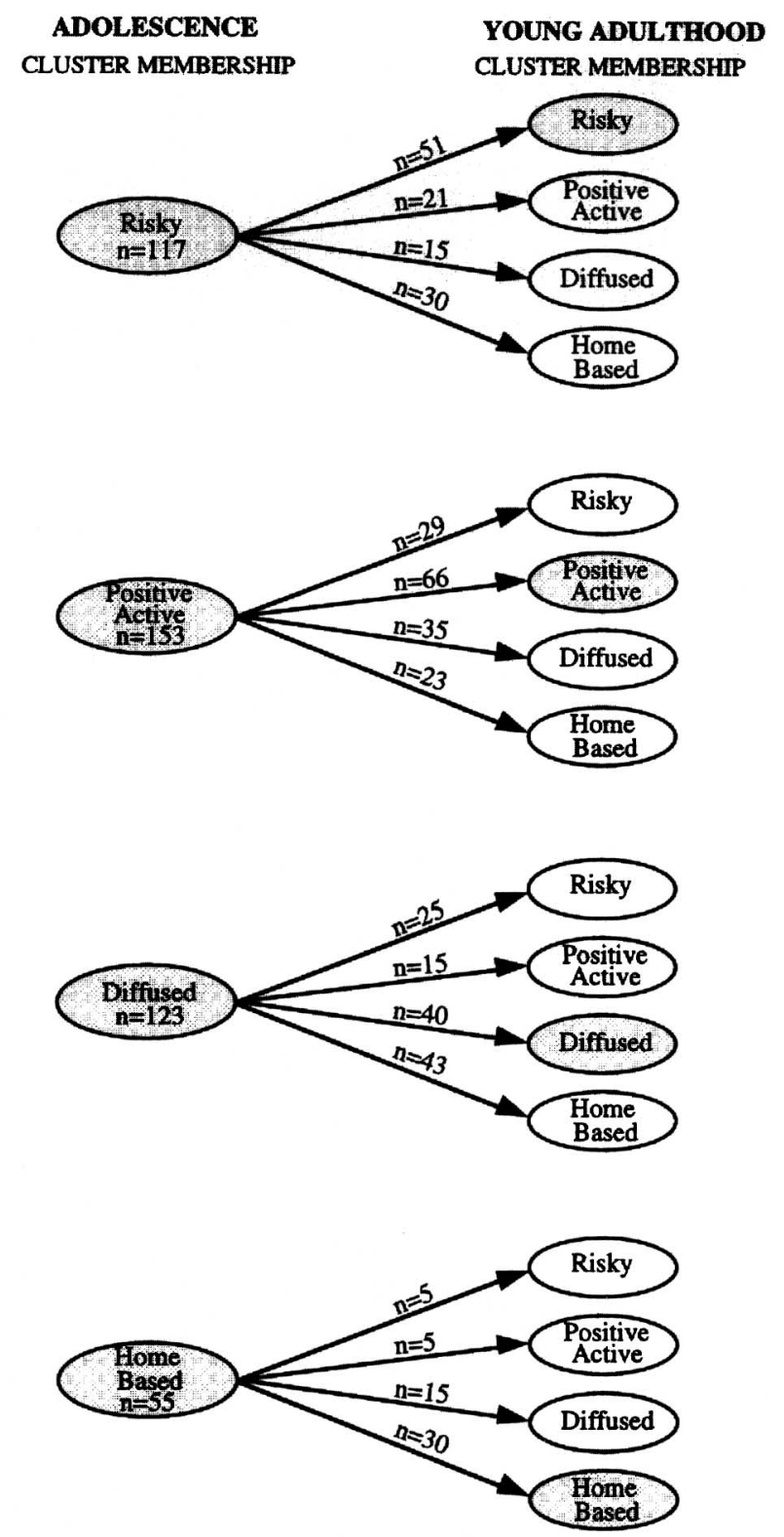

Fig. 1. Female leisure behavior pathways across the transition from adolescence to young adulthood $(N=448)$. 


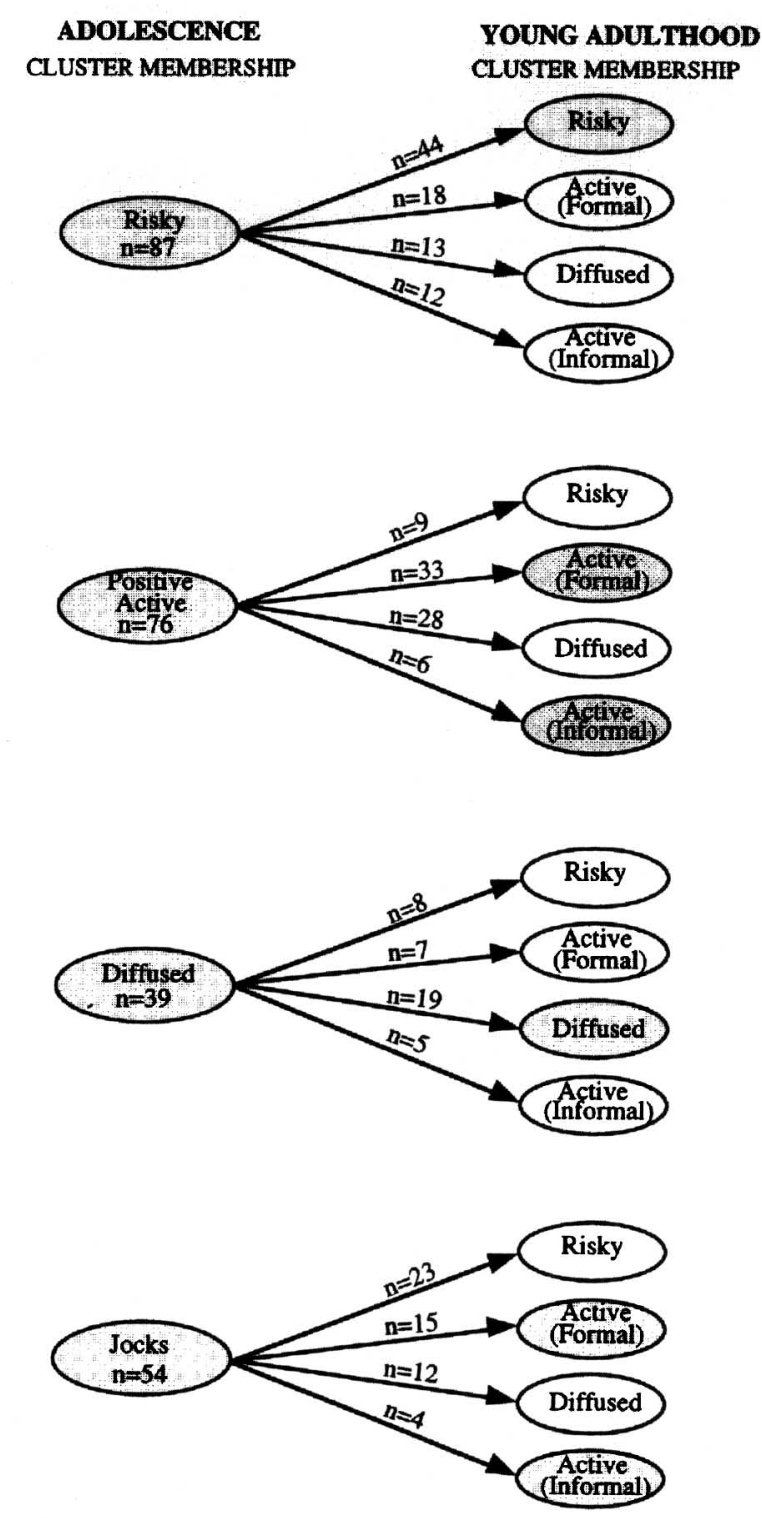

Fig. 2. Male leisure behavior pathways across the transition from adolescence to young adulthood $(N=256)$.

stable Risky (43\%), and the stable Positive Active (43\%) paths. The four least likely transitions were changing from being Home Based to becoming 
either Risky or Positive Active (each 9\%), changing from Risky to Diffused $(13 \%)$, and changing from Diffused to Positive Active (12\%) for the females. Stability in leisure behavior pattern tended to be the most common pathway into adulthood when compared to alternative paths. Forty-two percent of females overall were identified as having a similar leisure behavior pattern during adolescence and young adulthood.

In the case of males, stability was more difficult to identify since the same patterns were not all identified at adolescence and young adulthood. If, however, we consider Positive Active, Jocks, Active (Formal), and Active (Informal) to represent somewhat similar patterns (i.e., "Active") in that they involve high levels of involvement in activities that are generally socially valued by society when compared to Diffused and Risky leisure behavior patterns, $45 \%$ of males remained relatively stable in their leisure behavior pattern. Remaining Risky during young adulthood was the most common path for males who had been Risky during adolescence (51\%), while the least common path for this group was to become Diffused $(15 \%)$. Positive Active male adolescents were most likely to become Active (Formal or Informal) (51\%) and least likely to become Risky (12\%). Males who had been Diffused during adolescence were most likely to be identified as having the same pattern during young adulthood (49\%), and least likely to be later identified as Risky (21\%). Males who had been identified as Jocks during adolescence were most likely to become Risky during young adulthood (43\%) and least likely to become Diffused (22\%).

\section{DISCUSSION}

This discussion is based on the results obtained from a measure that was limited to twelve leisure activities; the activities included may not have allowed the principal leisure behaviors of some groups within the sample to be represented. For example, forms of leisure behavior such as listening to music and going to movies have not been included in this study. In addition, some leisure behavior patterns may incorporate different leisure behaviors during different points in the life span, and these differences may not have been captured by the twelve activities. Similarly, because we were interested in similarity and differences during the transition into young adulthood, we were limited in our analyses to items measured at both time points. Therefore, although time spent with romantic partner may be especially prevalent for some adolescents and young adults, because we had no indicator of that construct in high school, we did not include it in our analyses. Despite these limitations, the activities included in this study are indicative of what may be considered core leisure activities, or activities 
that are relatively accessible to interested people and that may form the foundation for leisure behavior patterns, and many of them can be participated in while spending time with one's romantic partner.

\section{Leisure Patterns}

The cluster analysis identified leisure patterns that were slightly different for males and females. A pattern labeled Positive Active was apparent for both genders during adolescence. Adolescents who participated in socially valued activities such as those that defined this pattern (volunteer work, clubs, religious activities) were referred to as being "conformist" by Hendry (1983, 1989), who suggested that such adolescents were likely to be from middle rather than lower socioeconomic backgrounds. This contention was not supported in the present study for the adolescent period, although in young adulthood, Positive Active females did have mothers with higher status occupations than Diffused and Home Based females. During young adulthood the Positive Active pattern was replaced by two different Active patterns for males. The most common of these two patterns involved leisure behavior that revolved around formal leisure structures including clubs, volunteer work, and religious activities, as during adolescence. The second active pattern was more informal and involved a mix of socially based (family and friends) and activity based (sports and reading) leisure participation.

The Risky pattern, present for males and females during both adolescence and young adulthood, was defined by higher frequencies of drug and alcohol use compared to peers for both genders during both points in the life span, and by doing "things just for kicks" at higher levels (except in the case of young adult males). Interestingly, females with the Risky pattern had the highest rates of hanging out with friends compared to their peers, while the same was not the case for males. Perhaps there is something about the social context of Risky behavior that is developmentally attractive to females yet unavailable from participation in other patterns of leisure behavior; in this study males appeared to achieve high levels of social contact with friends through patterns involving sport-related activities.

The Diffused pattern was apparent during both adolescence and young adulthood for both males and females, and was characterized by low participation in activities included in the study. However, the Diffused leisure pattern may have alternative interpretations. Subjects who were in the Diffused cluster may have been experimenting with a wide range of activities at very low levels, and thus did not have identifiable patterns of leisure behavior; alternatively, subjects identified as Diffused in their leisure pat- 
tern may have been involved in activities beyond the scope of the activities we measured. However, the patterns of transition for Diffused subjects illustrated in the next section suggests that the initial interpretation may be the correct understanding of the pattern. Diffused individuals appear to have been involved in low levels of core leisure activities as measured in this study.

Two patterns appeared that were not consistent between males and females. The Home Based pattern was apparent for females during both adolescence and young adulthood, and involved leisure activities that primarily occur in the home such as watching television and spending time with family. The fact that a similar pattern did not exist for males provides further evidence for the contention that females are socialized into leisure differently from males. The other pattern that was not apparent in both genders was the Jock pattern, which was evident for males during adolescence. For females, sports involvement during adolescence occurred alongside other "positive" activities such as volunteer work, club membership, and religious involvement for females. However, females as a whole did not indicate involvement in sports to the same extent as males. The adolescent Jock males appeared to be highly focused on sports involvement and on television viewing (watching sports, perhaps), and these sports-related activities appeared to occur in the company of friends.

\section{Interpreting Stable and Unstable Patterns}

A method of interpreting pathways may be found in Kleiber et al.'s (1986) discussion of transitional and relaxed leisure behaviors. These authors suggest that transitional leisure behaviors such as sports have developmental outcomes, and that when a developmental imperative is achieved a behavior is dropped. In terms of the present study, people who were Positive Active or Jocks during adolescence who became Diffused or Home Based during young adulthood may have done so because they derived all they could developmentally from the activities in which they were previously involved. However, individuals who were Home Based (females only) or Diffused during adolescence and who belonged to either cluster during young adulthood may have been consistently involved in relaxed leisure only (at least as represented here), which has no developmental importance, according to Kleiber et al. (1986).

Similar to Kleiber et al.'s ideas (1986) are those of Kelly (1987), who suggests that individuals have "core" leisure behaviors in which they participate throughout their lives, and "balance" leisure activities that meet specific developmental needs during a given period of life. Perhaps the 
stability found in this study is partially due to the inclusion of what could primarily be considered "core" leisure behaviors-activities that are relatively low cost, and somewhat easily accessible.

Finally, readers should note that the developmental pathways included in this study were based on the clustering of only twelve leisure behaviors. Subjects may have been involved in activities outside of those included in this study during either period of measurement which may have affected their level of participation in the behaviors under consideration. Chang et al. (1993) suggest that leisure interests may drastically change across developmental transitions; this study may not have examined forms of behavior that represent the leisure interests of young adults. At the same time, it should be recognized that since the patterns illustrated in the cluster solutions appear to make theoretical sense, the developmental pathways based on those patterns should also be accurate representations of the possible pathways of change and stability in patterns of leisure behavior.

\section{Leisure Behavior, Gender, and Transition}

Females and males remained stable in their leisure behavior pattern from adolescence to young adulthood at approximately the same rate (42\% and $45 \%$ respectively). The Risky leisure pattern was the most common pattern for males during both adolescence and young adulthood, while for females the most common pattern during adolescence was the Positive Active pattern and during young adulthood Home Based became the most prevalent pattern.

Interestingly, clearly similar patterns were found for females during both points in the life span, while the male patterns changed slightly during young adulthood. Male patterns during both adolescence and young adulthood did not include a clearly sedentary pattern of leisure behavior, whereas female patterns at both waves included a Home Based, sedentary pattern.

For females who were Diffused during adolescence, the most common pathway was to become Home Based during young adulthood, with remaining Diffused a close second. This pattern is quite different from the male pattern, since males who were Diffused during adolescence were most likely to remain Diffused or to develop an Active (Formal or Informal) leisure pattern. Therefore, adolescent females who were Diffused may have been experimenting with leisure activities, or not highly committed to a leisure pattern during adolescence. During adulthood, these females were most likely to choose a pattern of relative inactivity, which involves high levels 
of television viewing, reading and family time when compared to their peers.

In the case of Positive Active adolescents, the most likely path into young adulthood was that of remaining active, for both males and females. The least likely pattern during young adulthood for a Positive Active adolescent was Home Based for females, and Risky for males (if we consider Formal and Informal Active young adult patterns to be similar to Positive Active). This finding suggests that the likelihood of an adolescent female who is highly active in a range of leisure activities (primarily socially valued activities) becoming "a couch potato" during their young adulthood is low. Adolescent males who are highly involved in socially valued leisure activities are unlikely to become highly involved in risky leisure behaviors such as drinking and using drugs. Interestingly, males who are identified as "jocks" during adolescence appear to be most likely to adopt a Risky pattern of leisure behavior during their young adulthood; this finding is in keeping with research suggesting that athletes may be more likely to be sensation seekers who are attracted to new experiences involving high risk (Young, 1990). An examination of the means for drinking and doing risky things for a kick in 12th grade indicates that the Jocks are second only to the Risky males, foreshadowing the move by many into the Risky cluster in young adulthood. The connection between drinking and sports appears even earlier in this sample, with participation in team sports in 10th grade being linked to increases in substance use across the high school years (Eccles and Barber, in press).

\section{FURTHER RESEARCH}

The study reported herein examined leisure behavior across a life transition without specifically examining events that may have occurred to individuals during the period from adolescence to young adulthood. Stability and instability in leisure behavior is likely to be influenced by the contextual changes that accompany life transitions; such changes may offer explanations for the patterns observed in the present research. Further research should examine the influence of variables related to the contexts of young adulthood, including such transition events as the influence of a serious relationship and leaving the parental home, on individuals' leisure behavior patterns. The present study sought to examine the possibility of leisure behavior patterns during adolescence and young adulthood, and to determine the nature of stability and instability during the transition into young adulthood. Further research should seek to predict stability and instability in various leisure behavior patterns based on the occurrence of contextual 
changes associated with the transition from adolescence to young adulthood.

\section{REFERENCES}

Adams, G. R., Shea, J., and Fitch, S. A. (1979). Toward the development of an objective assessment of ego-identity status. J. Youth Adolesc. 8: 223-237.

Agnew, R., and Petersen, D. M. (1989). Leisure and delinquency. Social Problems 36: 332-350. Aldenderfer, M. S., and Blashfield, R. K. (1984). Cluster Analysis. Sage, Newbury Park, CA.

Berk, L., and Goebel, B. (1987). Patterns of extracurricular participation from high school to college. Am. J. Educ. 95: 468-485.

Chang, A. F., Rosenthal, T. L., Bryant, E. S., Rosenthal, R. H., Heidlage, R. M., and Fritzler, B. K. (1993). Comparing high school and college students' leisure interests and stress ratings. Beh. Res. Ther. 31: 179-184.

Colley, A. (1984). Sex roles and explanations of leisure behavior. Leisure Studies 3: 335-341.

Crawford, D. W., and Huston, T. L. (1993). The impact of the transition to parenthood on marital leisure. Personal. Social Psychol. Bull. 19: 39-46.

Crompton, J., Vedlitz, A., and Lamb, C. W. (1981). Recreational activity clustering among adolescents. Res. Quart. Exercise Sport 52: 449-457.

Csikszentmihalyi, M., and Larson, R. (1984). Being Adolescent: Conflict and Growth in the Teenage Years. Basic Books, New York.

Eccles, J. S., and Harold, R. D. (1991). Gender differences in sport involvement: Applying the Eccles' Expectancy-Value Model. J. Appl. Sport Psychol. 3: 7-35.

Eccles, J. S., Wigfield, A., Flanagan, C. A., Miller, C., Reuman, D. A., and Yee, D. (1989) Self-concepts, domain values, and self-esteem: Relations and changes at early adolescence. J. Personal. 57: 283-310.

Ellis, G. D., and Rademacher, C. (1987). Development of a typology of common adolescent free time activities: A validation and extension of Kleiber, Larson, and Csikszentmihalyi. J. Leisure Res. 19: 284-292.

Entwisle, D. R., and Astone, N. M. (1994). Some practical guidelines for measuring youth's race/ethnicity and socioeconomic status. Child Develop. 65: 1521-1540.

Fasick, F. A. (1988). Patterns of formal education in high school as rites de passage. Adolescence 23: $457-468$.

Fine, G. A., Mortimer, J. T., and Roberts, D. F. (1990). Leisure, work, and the mass media. In Feldman, S. S., and Elliot, G. R. (eds.), At the Threshold: The Developing Adolescent. Harvard University Press, Cambridge, MA.

Furlong, A., Campbell, R., and Roberts, K. (1990). The effects of post-16 experiences and social class on the leisure patterns of young adults. Leisure Studies 9: 213-224.

Garton, A. F., and Pratt, C. (1991). Leisure activities of adolescent school students: Predictors of participation and interest. J. Adolesc. 14: 305-321.

Greene, A. L., Wheatley, S. M., and Aldava, J. F. (1992). Stages on life's way: Adolescents' implicit theories of the life course. J. Adoles. Res. 7: 364-381.

Hartnagel, T. F. (1996). Cannabis use and the transition to young adulthood. J. Youth Adolesc. 25: $241-258$.

Henderson, K. A., and Bialeschki, M. D. (1989). A Leisure of One's Own: A Feminist Perspective on Women's Leisure. Venture Publishing, State College, PA.

Hendry, L. B. (1989). The influence of adults and peers on adolescents' lifestyles and leisure styles. In Hurrelman, K., and Engel, U. (eds.), The Social World of Adolescents: International Perspectives. Walter de Gryter, Berlin.

Hendry, L. B. (1983). Growing Up and Going Out: Adolescents and Leisure. University Press, Aberdeen.

Hendry, L. B., Shucksmith, J., Love, J. G., and Glendinning, A. (1993). Young People's Leisure and Lifestyles. Routledge, London. 
Horna, J. (1989). The leisure component of the parental role. J. Leisure Res. 21: 228-241.

Iso-Ahola, S. E. (1980). The Social Psychology of Leisure and Recreation. Wm. C. Brown, Dubuque, IA.

Johnson, M. P., Huston, T. L., Gaines, S. O., and Levinger, G. (1992). Patterns of married life among young couples. J. Social Person. Relation. 9: 343-364.

Kelly, J. R. (1987). Freedom To Be: A New Sociology of Leisure. Macmillan, New York.

Kelly, J. R. (1983). Leisure Identities and Interactions. George Allen and Unwin, Winchester, MA.

Kleiber, D. A., and Kelly, J. R. (1980). Leisure, socialization, and the life cycle. In Iso-Ahola, S. E. (ed.), Social Psychological Perspectives on Leisure and Recreation. Charles C. Thomas, Springfield, IL.

Kleiber, D. A., Larson, R., and Csikszentmihalyi, M. (1986). The experience of leisure in adolescence. J. Leisure Res. 18: 169-176.

Larson, R., and Richards, M. H. (1994). Divergent Realities: The Emotional Lives of Mothers, Fathers, and Adolescents. Basic Books, New York.

Marcia, J. E. (1966). Development and validation of ego identity status. J. Personal. Social Psychol. 3: 551-558.

Maudlin, T., and Meeks, C. B. (1990). Sex differences in children's time use. Sex Roles 22: $537-554$.

Norusis, M. J. (1990). SPSS Base System Users Guide. SPSS, Chicago.

Rapoport, R., and Rapoport, R. N. (1975). Leisure and the Family Life Cycle. Routledge and Kegan Paul, Boston.

Raymore, L. A. (1995). Leisure behavior and the transition from adolescence to young adulthood. Leisure Studies 14: 202-216.

Romesburg, H. C. (1979). Use of cluster analysis in leisure research. J. Leisure Res. 11: 144-153

Schulenberg, J., Wadsworth, K. N., O'Malley, P. M., Bachman, J. G., and Johnston, L. D. (1996). Adolescent risk factors for binge drinking during the transition to young adulthood: Variable- and pattern-centered approaches to change. Develop. Psychol. 32: 659-674.

Shaw, S. M., Kleiber, D. A., and Caldwell, L. L. (1995). Leisure and identity formation in male and female adolescents: A preliminary examination. J. Leisure Res. 27: 245-263.

Sherrod, L. R., Haggerty, R. J., and Featherman, D. L. (1993). Introduction: Late adolescence and the transition to adulthood. J. Res. Adolesc. 3: 217-226.

Silbereisen, R. K., Noack, P., and von Eye, A. (1992). Adolescents' development of romantic friendship and change in favorite leisure contexts. J. Adoles. Res. 7: 80-93.

Tinsley, H. E., Barrett, T. C., and Kass, R. A. (1977). Leisure activities and need satisfaction. J. Leisure Res. 9: 110-120.

Tinsley, H. E., and Johnson, T. L. (1984). A preliminary taxonomy of leisure activities. $J$. Leisure Res. 16: 234-244.

Tinsley, H. E., and Tinsley, D. J. (1986). A theory of the attributes, benefits, and causes of leisure experience. Leisure Sci. 8: 1-45.

Witt, P. A., and Goodale, T. L. (1981). The relationship between barriers to leisure enjoyment and family stages. Leisure Sci. 4: 29-49.

Young, T. J. (1990). Sensation seeking and self-reported criminality among student athletes Percept. Motor Skills 70: 959-962. 